\title{
Los sistemas de nombramiento de magistrados en el Derecho Comparado y en el Perú
}

Manuel J. Miranda Canales* http://dx.doi.org/10.21503/lex.v9i8.401

* Doctor en Derecho, ex Consejero del Consejo Nacional de la Magistratura, ex Presidente de la Corte Superior de Justicia del Cono Norte de Lima, Vocal Supremo (P).

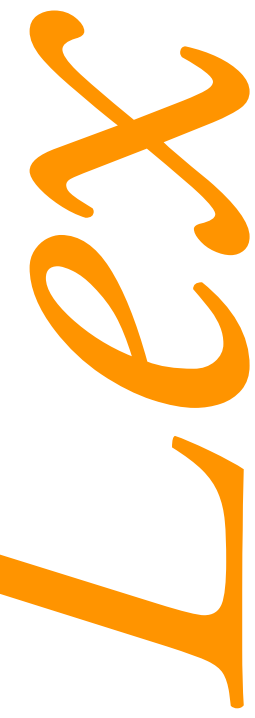





\section{Los sistemas de nombramiento de los magistrados}

\subsection{Consideraciones previas}

Como deba ser la carrera judicial y, si acaso, esa carrera haya de contemplar o no un análisis alternativo, es cuestión que depende, en último análisis, del lugar y las características que se adscriban a la función jurisdiccional al interior del Estado. En otros términos, la carrera judicial y el sistema de nombramientos que lleva asociada esa misma carrera es una cuestión que depende estrictamente del lugar que se asigna a los jueces al interior del sistema político y legal.

El Dr. Carlos Peña Gonzales, en su artículo titulado, "Sobre la Carrera Judicial y el Sistema de Nombramientos", dice:

La carrera judicial no es una cuestión jurídica y políticamente inocente que pueda ser resuelta con ánimo desaprensivo; cosa distinta, se trata de una cuestión que atinge centralmente a la fisonomía que sea capaz de exhibir el Estado de Derecho. La carrera judicial expresa o trasunta el lugar que se le asigna a los jueces al interior del Estado. ${ }^{1}$

En términos generales, los sistemas judiciales occidentales, entendiendo por tales, en lo fundamental, los sistemas de Europa occidental, han transitado en el curso de este siglo, desde un modelo con fuerte acento jerarquizado o burocrático (sistema técnico-burocrático) a un modelo que acentúa la vinculación de la judicatura al sistema político y la sociedad civil, llamado modelo democrático.

El sistema técnico-burocrático se basa en la idea de que el personal de la judicatura debe ser sometido a un intenso proceso de selección por concursos previa obtención de estudios

PEÑA GONZALES, Carlos. Sobre la Carrera Judicial y el Sistema de Nombramientos. Academia de la Magistratura: Lima, $\mathrm{N}^{\circ}$ 1, enero 1998. p.10. 
especializados. La idea que subyace a este sistema es que la judicatura presta un importante servicio público de características esencialmente técnicas y que el mero título de abogado no basta para ejercerla.

El sistema técnico-burocrático evolucionó hacia el modelo democrático, porque aquel modelo incentivó, en los hechos, a un tipo de juez aséptico, puramente técnico, despojado de vinculaciones con las valoraciones sociales dominantes y aislado de la sociedad civil y política. En razón de estos defectos, el modelo democrático, si bien mantiene el sistema de elección técnica, al menos, hasta un cierto nivel de la judicatura, hace participar a todos los sectores del Estado en el manejo de los sistemas de selección, reclutamiento y ascenso de jueces mediante la institución del Consejo de la Magistratura.

El tema de cuál sea el mejor sistema de nombramiento de jueces es un típico dilema de la política pública. Se trata de un problema en el que no sólo han de convocarse variables conceptuales, como la necesidad de que los jueces sean independientes o la mera instauración de reglas, sino de un problema en el que también han de convocarse variables de hecho o empíricas, como la calidad del sistema político, la existencia o no de una genuina burocracia judicial, y la vigencia o no de las normas legales sobre la materia.

En resumen, el perfil del juez y la selección de los magistrados son temas complejos que deben ser abordados de un modo técnico y científico.

\subsection{Importancia del tema}

Los mecanismos de reclutamiento de los magistrados judiciales han suscitado, desde tiempo atrás, hondas preocupaciones en la literatura especializada. Quizá por eso, la doctrina ha calificado a estos procedimientos de "fundamentales", pues son poseedores de una especial importancia para cualquier sociedad.

Las razones que justifican tal calificativo son diversas. Puede advertirse que se trata de la estructuración de uno de los más significativos órganos estatales, como es el Poder Judicial. Hay aquí, pues, un problema político de primera magnitud, puesto que de la manera en que se originen y cubran los tribunales, dependerá, en alguna medida, el organigrama total de un Estado.

El tema del reclutamiento de los jueces implica también una cuestión de eficacia, de buena administración, de prudencia en el desempeño de una tarea de bien común. La misión del legislador, cuando norma sobre la composición de los tribunales, no consiste en crear entes puros, cuerpos sin vitalidad u órganos inertes. Por el contrario, se trata de proyectar e integrar 
instituciones básicamente humanas en cuanto trabajan juiciosa y razonablemente para la obtención de los valores jurídicos fundamentales de la persona, como la cooperación, la paz, el orden, la solidaridad y la justicia.

\subsection{Selección e independencia del juez}

Con mucha frecuencia, se ha insistido en la íntima conexión que media entre las vías de selección de los jueces y la posterior autonomía de estos en el ejercicio de sus funciones específicas.

Se ha dicho que la elección popular de los magistrados los ha hecho independientes de los otros dos poderes del Estado (sobre todo, por no provenir de éstos). El sistema de oposiciones, a su vez, ha merecido elogios parecidos, ya que el juez sería tal en virtud de sus méritos propios y sus condiciones personales técnicamente evaluadas y no por el criterio discrecional de los integrantes de los poderes llamados "políticos".

\section{Las técnicas de selección judicial en el Derecho Comparado}

\subsection{Mecanismos simples}

Normalmente, es un ente estatal quien selecciona a los jueces. Se denomina simple a los procedimientos de selección cuando es un solo órgano de gobierno o ente estatal quien procede a elegir al magistrado y, complejos, cuando en tal operación, intervienen dos o más órganos. Entre los procedimientos simples aparecen los siguientes:

\subsubsection{Elección popular}

Las razones que han justificado el llamado al cuerpo electoral para nombrar a los jueces son varias. Se ha dicho que, siendo el pueblo quien elige a los autores de la ley, es razonable que elija, asimismo, a quienes deban interpretarla y aplicarla.

\subsubsection{El poder ejecutivo}

La transferencia de los poderes de las antiguas monarquías en los Estados contemporáneos ha hecho que quedara en manos de algunos jefes de Estado la selección exclusiva de ciertos magistrados.

La Constitución de Brasil preceptúa en su Art. 84 inc. XIV, que: "Compete privativamente al Presidente de la República: nombrar, a propuesta del Senado Federal, a los Ministros 
del Supremo Tribunal Federal y Tribunales Superiores" ${ }^{(2)}$ e igualmente la Constitución de la República de Chile en su Artículo 75, establece que "Los Ministros y Fiscales de la Corte Suprema, de las Cortes de Apelaciones y los Jueces Letrados serán nombrados por el Presidente de la República" ${ }^{(3)}$ Similar disposición contiene la Constitución Argentina en su Art. 99 inc. $4 .{ }^{4}$

\subsubsection{El Poder Legislativo}

Diversos Estados han encomendado a sus respectivos parlamentos la tarea de seleccionar los magistrados. La Constitución Política de Bolivia, en su art. 125, preceptúa que los magistrados de la Corte Suprema serán elegidos por la Cámara de Diputados a propuesta del Senado y el Art. 127 establece que "son atribuciones de la Corte Suprema proponer ternas al Senado para la elección de los Vocales de las Cortes Superiores del Distrito". 5

La elección parlamentaria de los jueces ha contado, por lo común, con más detractores que defensores. En general, se previene contra las manipulaciones políticas a que puede prestarse el sistema y las consiguientes secuelas en el futuro comportamiento del juez designado. Por ende, no se le considera propicio para la independencia del Poder Judicial.

\subsubsection{La cooptación: selección de los jueces por el Poder Judicial}

No es frecuente atribuir al propio Poder Judicial, (por lo común, la Corte Suprema), la nominación de magistrados judiciales, con exclusividad; sin embargo, este sistema existe.

\subsubsection{El Consejo Superior de la Magistratura}

En 1947, la Constitución italiana introdujo algunos cambios fundamentales en la mecánica de nominación de magistrados. Por un lado, declaró que estos serían designados por concurso (art. 106). Por otro, instituyó un Consejo Superior de la Magistratura al que corresponde, según las normas de organización judicial, "los nombramientos, las asignaciones, los traslados, los ascensos y las medidas disciplinarias relativas a los magistrados" (art. 105). ${ }^{6}$

\footnotetext{
Constituicao da Republica Federativa do Brasil. Editora Saraiva: Sao Paulo, 33 edición, actualizada y ampliada. 2004.

Constitución Politica de la República de Chile. Instituto de Derecho Público Comparado. Información obtenida vía Internet. 2004.

4 Constitución de la Nación Argentina. Edición del País: Buenos Aires, 8va. edición, 2002.

5 Constitución Politica del Estado de Bolivia. Reformada en 1994, Concordada, Centro de Estudios Forenses. "Agustín Aspiazu": La Paz.

6 Constitución Politica de Italia, información obtenida vía Internet, traducción libre, 2003.
} 
La Constitución colombiana, en el inc. 2 del Artículo 256, prescribe como una de las atribuciones del Consejo Superior de la Judicatura: elaborar las listas de candidatos para la designación de funcionarios judiciales y enviarlas a la entidad que debe hacerla.?

En el Primer Congreso Iberoamericano de Derecho Constitucional, efectuado en México entre el 25 y 30 de agosto de 1975, se aprobó una sexta recomendación a propuesta del jurista mexicano Héctor Fix - Zamudio, con el siguiente tenor:

En la reorganización del aparato judicial latinoamericano, resulta conveniente la introducción del Consejo Judicial o de la Magistratura, el que deberá ser organizado teniendo en cuenta las peculiares características de la realidad constitucional latinoamericana. Debe estar integrado mayoritariamente por funcionarios judiciales, cuya designación provenga de los mismos jueces, sin perjuicio de la representación de otros poderes y organizaciones, con el objeto de evitar que el organismo judicial se transforme en un cuerpo cerrado y estratificado. Su función será la de vigilar el cumplimiento de las garantías judiciales, especialmente el nombramiento, promoción y responsabilidad de los jueces y el establecimiento de verdaderas carreras políticas judiciales. ${ }^{8}$

El proceso de selección normal de los jueces se deriva así a un cuerpo particular, en cuya integración confluyen distintos sectores (Poder Ejecutivo, jueces, legisladores, docentes universitarios, etc.).

La tecnificación de los métodos para escoger a los jueces, por concurso, trata, por último, de encontrar un sistema en el que atienda, tanto a los méritos del candidato, como al juicio múltiple de los grupos más directamente conectados con el quehacer judicial.

\subsubsection{El Poder Judicial}

En España, la Escuela Judicial (que es un organismo autónomo integrado en el Ministerio de Justicia) tiene competencia para la selección, formación y perfeccionamiento de los funcionarios al servicio de la justicia, como dice la Dra. Amparo Camazón Limacero, al comentar la Ley Orgánica del Poder Judicial de España. ${ }^{9}$

PEREYRA MONSALVE, Luis César. Constitución Politica de Colombia. Poligráficas: Medellín, 1998.

PLANAS, Pedro. "El Consejo de la Magistratura en América Latina. Anotaciones para un estudio comparativo", en: Revista del Foro, Colegio de Abogados de Lima, Año LXXXVI Nº 2 Junio-Diciembre 1998, p. 43.

9 CAMAZON LIMACERO, Amparo. Estatuto Judicial. La Ley Orgánica del Poder Judicial. La Carreras Judicial. Consejo General del Poder Judicial, Escuela Judicial: Barcelona. 


\subsubsection{Otros casos}

En otros casos, son nombrados por el Duque, como en Luxemburgo o por el Papa, como en el Vaticano, o por el Rey, como en Bélgica y Holanda.

\subsection{Mecanismos complejos}

En los procedimientos complejos de selección de magistrados intervienen dos o más órganos de selección. En este caso, la responsabilidad es compartida por varios cuerpos, sin perjuicio, claro está, de que también formalmente uno de ellos pueda actuar como órgano de designación.

Así, por ejemplo, nombra el Poder Ejecutivo a propuesta del Poder Legislativo o viceversa; o nombra el Poder Ejecutivo a propuesta del Consejo de la Magistratura; o nombra el Poder Ejecutivo a propuesta del Poder Judicial; o nombra el Poder Ejecutivo a propuesta del Colegio de Abogados; o nombra el Poder Ejecutivo a propuesta de las Municipalidades; tal como lo expresa el Dr. Nestor Pedro Sagues, en su libro Reforma Judicial: los Sistemas de Designación de Magistrados y la Escuela Judicial en el Derecho Argentino y Comparado.

\section{El sistema de elección de magistrados en el Perú}

\subsection{Marco constitucional}

Uno de los campos donde la Constitución peruana de 1993 introdujo un alentador conjunto de positivas novedades ha sido el referido a la administración de justicia y a los órganos involucrados en dicha función. Cabe mencionar, entre los principales, la sustantiva ampliación de las atribuciones del Consejo Nacional de la Magistratura (CNM), así como la creación de la Academia de la Magistratura (AMAG), instaurándose, con ello, un nuevo sistema de selección, nombramiento, formación y capacitación de magistrados.

La vigente Carta Constitucional confiere al Consejo Nacional de la Magistratura las potestades de seleccionar, nombrar, promover y destituir a los magistrados de todos los niveles del Poder Judicial y del Ministerio Público, excluyendo toda participación, en estas funciones, a los órganos políticos quienes tampoco intervienen en la designación o composición de los miembros del Consejo. A su vez, la Academia de la Magistratura es la encargada de la capacitación de los magistrados. 


\subsection{El Consejo Nacional de la Magistratura}

\subsubsection{Origen y fundamento de los Consejos de la Magistratura}

Aunque la creación de los Consejos Judiciales o Consejos de la Magistratura viene siendo un fenómeno muy difundido en diversos países de Latinoamérica, lo cierto es que tanto su ubicación y atribuciones que le corresponden difieren significativamente en las distintas experiencias nacionales, al punto que no puede hablarse, con propiedad, de un "modelo único” en esta materia.

Para entender el surgimiento y el fundamento de estos Consejos de la Magistratura en Latinoamérica, debe tenerse en cuenta que suponen la recepción de la experiencia de algunos países de Europa Continental en busca de dar respuesta a la preocupación de cómo efectivizar el mejor autogobierno y la adecuada administración del Poder Judicial, tanto con respecto al personal del sector, como a la gestión de su presupuesto y recursos económicos. Ello, a su vez, a fin de superar la injerencia de los órganos políticos (Gobierno y Parlamento) en la marcha del órgano judicial, expresada en los riesgos de falta de independencia, politización y partidarización.

Conviene tener presente que, actualmente, en Latinoamérica, no existe un criterio uniforme sobre el órgano adecuado o la forma más apropiada para realizar y garantizar con eficiencia este autogobierno y administración del Poder Judicial.

La tradición y experiencia jurídico-política de los distintos países ha ejercido sustantiva influencia e incidencia en cada caso. Podrían ubicarse hasta tres grandes opciones para acometer este problema:

1. En primer lugar, estarían los ordenamientos donde el gobierno y la administración del Poder Judicial, son ejercidos por la instancia de mayor jerarquía de dicho órgano, es decir, la Corte Suprema ("modelo del juez-administrador"). Este ha sido o es el caso de los países como Argentina, Bolivia, Ecuador, Guatemala, Honduras, Méjico, Nicaragua, Panamá, Paraguay y Uruguay. Cabe anotar, sin embargo, que tanto en Bolivia como en el Ecuador, ya se han adoptado, mediante reforma constitucional, Consejos de la Magistratura, aunque ambos se encuentran pendientes de regulación legal y/o implementación.

2. En segundo lugar, se encuentran los sistemas donde se crean órganos especializados anexos a la Corte Suprema, con relativa autonomía (a veces sólo formal) de ésta; tal es el caso de países como Chile y Costa Rica.

3. En tercer lugar, constituyendo la experiencia más reciente, se encuentran los sistemas que cuentan con Consejos de la Magistratura, como órganos especializados y autónomos. 
Su origen se encuentra en la experiencia europea de la postguerra, a través del Consejo Superior de la Magistratura de Francia (1946), el Consejo Superior de la Magistratura de Italia (1948) y el Consejo General del Poder Judicial de España (1978).

Los principales antecedentes en Latinoamérica los podemos hallar en la experiencia de algunas provincias argentinas y en el Consejo Nacional de Justicia que creó, en el Perú, el gobierno militar a fines del año de 1969. La versión más propia la encontramos en el Consejo de la Judicatura de Venezuela (instaurado en 1969) como órgano encargado de la independencia, eficiencia, disciplina y decoro de los tribunales, así como de garantizar a los jueces los beneficios de la carrera judicial.

Los fines que se persiguen con la adopción de los Consejos de la Magistratura son:

a) Despartidarizar a las instituciones judiciales. Fomentar que el ingreso y la promoción en la carrera judicial se basen en los méritos del candidato

b) Que el acceso a las plazas judiciales se gane "por derecho propio" y no por obsequio o premio de quien nombra.

c) Reclutar en la carrera judicial a los mejores sin pautas discriminatorias respetando las directrices constitucionales de igualdad y selección por idoneidad.

d) Robustecer la autonomía de la judicatura en cuanto a los restantes poderes del Estado o a los grupos y factores de poder allí involucrados, así como perfeccionar su eficacia.

En consecuencia, si bien las competencias y funciones de los Consejos de la Magistratura o Judicatura no son uniformes en el Derecho Comparado ni en las recientes experiencias latinoamericanas, puede señalarse que su labor suele abarcar aspectos tales como:

a) Selección, nombramiento y promoción del magistrado

b) Remoción y destitución de los magistrados

c) Administración y gobierno del Poder Judicial

d) Inspección y control

e) Potestad normativa y reglamentaria

\subsubsection{El Consejo Nacional de la Magistratura en el Perú}

La Constitución peruana de 1933 disponía que los Vocales y Fiscales de la Corte Suprema fuesen designados por el Congreso entre diez candidatos propuestos por el Poder Ejecutivo. 
A su vez, disponía que los magistrados de las Cortes Superiores (segunda instancia) fuesen nombrados por el Poder Ejecutivo a propuesta en terna doble de la Corte Suprema. Los jueces y agentes fiscales (primera instancia) eran designados también por el Poder Ejecutivo, pero a propuesta (en terna doble) de las respectivas Cortes Superiores. Por último, los Jueces de Paz Letrados y No Letrados eran directamente nombrados por cada Corte Superior. ${ }^{10}$

En diciembre de 1969, el gobierno militar encabezado por el General Juan Velasco Alvarado, creó el Consejo Nacional de Justicia, órgano que estaba compuesto por dos delegados del Poder Ejecutivo, dos del Congreso (cuyas funciones ejercía el propio Ejecutivo), dos delegados del Poder Judicial, uno de la Federación Nacional de Colegios de Abogados del Perú, uno del Colegio de Abogados de Lima y otros dos designados por las Facultades de Derecho nacionales más antiguas. El Consejo efectuaba la designación de magistrados, a partir de los candidatos propuestos por el Poder Judicial, la Federación Nacional de Colegio de Abogados y el Colegio de Abogados respectivo. Los candidatos eran sometidos a evaluación y entrevista personal.

El Consejo Nacional de Justicia logró, posteriormente, ampliar algunas de sus atribuciones en la designación de magistrados; incluso sólo elevaba al Ejecutivo la propuesta de un candidato para cada cargo, obteniendo siempre el nombramiento respectivo. Esta práctica se rompió en 1976, cuando el Gobierno descartó la propuesta del Consejo, nombrando como Vocal de la Corte Suprema a otra persona que no había participado en el concurso, por lo que el Presidente y el Vicepresidente del Consejo, renunciaron. Posteriormente, la Constitución Política del Perú de 1979 reguló, en el Capítulo X del Título IV, la existencia, composición y funciones del Consejo Nacional de la Magistratura, en sus Artículos 245, 246 y 247.

La Carta de 1979 sólo otorgaba competencia al Consejo de la Magistratura en materia de formulación de propuestas para el nombramiento de los magistrados de la Corte Suprema y Cortes Superiores, cuya designación continuaba encomendada al Presidente de la República, conforme al Reglamento de los Consejos de la Magistratura que se elaboró cuando el autor de este artículo fue Consejero del Consejo Nacional de la Magistratura, publicado el 26 de Mayo de 1991, en cumplimiento de la Resolución No 018-91-CNM.

El nombramiento presidencial de los magistrados de la Corte Suprema quedaba sometido a la ratificación del Senado. Las propuestas para el nombramiento presidencial de los magistrados de primera instancia y cargos inferiores se encomendaban a los Consejos Distritales de la Magistratura. Se establecía que las propuestas debían efectuarse previo concurso de méritos y evaluación personal de candidatos.

10 Constitución Política del Perú de 1933, (29 de Marzo de 1933) Información obtenida vía Internet, 2004. 
En cuanto a su composición, el Consejo Nacional de la Magistratura, según la Constitución e 1979, estaba integrado por siete miembros: el Fiscal de la Nación, quien lo presidía, dos representantes de la Corte Suprema, un representante de la Federación Nacional de Colegios de Abogados del Perú, otro del Colegio de Abogados de Lima, y dos representantes de las Facultades de Derecho del país. El mandato de cada uno de ellos tenía una duración de tres años. Por su parte, los Consejos Distritales de la Magistratura estaban presididos por el Fiscal Decano del Distrito e integrados por dos magistrados más antiguos de la Corte Superior y por dos representantes del Colegio de Abogados de la Jurisdicción.

Cabe anotar que las potestades de investigar la conducta funcional de los jueces y de imponer sanciones disciplinarias siguieron conferidas a la Corte Suprema y no al Consejo. Se estableció que el Consejo Nacional de la Magistratura recibiera las denuncias que se presentaban por la actuación de los Vocales de la Corte Suprema, calificándolas y remitiéndolas al Fiscal de la Nación, si hubiera la presunción de la comisión de algún delito, o a la propia Corte Suprema, para la imposición de sanciones disciplinarias. Estas situaciones la experimentamos cuando fuimos miembros del Consejo Distrital de la Magistratura de Ica y del Consejo Nacional de la Magistratura durante los años de 1983 a 1984 y de 1989 a 1992, en representación del Colegio de Abogados de Ica y de las Facultades de Derecho del país, respectivamente.

La Constitución Política de 1993 introdujo modificaciones muy significativas en cuanto a las funciones del Consejo Nacional de la Magistratura que resultan positivamente ampliadas en cuanto a su composición.

En relación a sus funciones, el Art. 154 establece que éstas son:

a) Nombrar, previo concurso público de méritos y evaluación personal, a los jueces y fiscales de todos los niveles, salvo aquellos que provienen de elección popular. Dicho nombramiento requiere el voto conforme de los dos tercios del número legal de sus miembros.

b) Ratificar a los jueves y fiscales de todos los niveles cada siete años; dicho proceso de ratificación es independiente de las medidas disciplinarias. Los magistrados no ratificados no pueden reingresar al Poder Judicial o al Ministerio Público.

c) Aplicar la sanción de destitución a los Vocales de la Corte Suprema y Fiscales Supremos y, a solicitud de la Corte Suprema o de la Junta de Vocales Supremos, respectivamente, a los jueces y fiscales de todas las instancias. La resolución final motivada, y con previa audiencia del interesado, es inimpugnable.

d) Extender a los jueces y fiscales el título oficial que los acredita. 
En cuanto a la composición del Consejo Nacional de la Magistratura, el art. 155 establece que son sus miembros conforme a la ley de la materia:

1. Uno elegido por la Corte Suprema, en votación secreta en Sala Plena.

2. Uno elegido, en votación secreta por la Junta de Fiscales Supremos.

3. Uno elegido por los miembros de los Colegios de Abogados del País, en votación secreta, convocada por la Oficina Nacional de Procesos Electorales, según la Resolución del Consejo Nacional de la Magistratura No 06-99 CNM de 19 de Noviembre de 1999, publicada en el diario "El Peruano" el 23 de noviembre de ese mismo año.

4. Dos elegidos, en votación secreta, por los miembros de los demás colegios profesionales del país, conforme a ley; convocada por la Oficina Nacional de Procesos Electorales, según la Resolución del Consejo Nacional de la Magistratura No 06-99 CNM de 19 de Noviembre de 1999, publicada en el diario El Peruano el 23 de noviembre de ese mismo año.

5. Uno elegido, en votación secreta por los rectores de las universidades nacionales.

6. Uno elegido, en votación secreta, por los rectores de las universidades particulares.

El mismo artículo contempla la posibilidad de que el número de miembros del Consejo Nacional de la Magistratura pase de siete a nueve, siendo los dos adicionales elegidos por el propio Consejo, en votación secreta, de las listas propuestas por instituciones representativas de los sectores laborales y empresariales.

Es interesante anotar que un cambio introducido por la Constitución del 93 se refiere a la Presidencia del Consejo que la Carta del 79 asignaba necesariamente al Fiscal de la Nación (Ley 26397, art. 36º), y ahora se dispone que el Presidente del Consejo será elegido por los Consejeros, en votación secreta, por la mitad más uno del pleno; su cargo dura un año, con la posibilidad de la reelección inmediata por una sola vez.

Si bien mantiene la exclusión de toda participación de los Poderes Ejecutivo y Legislativo en la elección de representantes como integrantes del Consejo, cabe destacar que se introducen algunas modificaciones en la composición de dicho órgano. Ello fortalece su carácter pluralista e incrementa su representatividad al contemplar la pertenencia como miembros de personas ajenas a la profesión de abogados, que serían los dos elegidos por los colegios profesionales distintos a los Colegios de Abogados. Similar posibilidad podría darse en caso de adoptarse la participación de consejeros provenientes de organizaciones laborales y empresariales, cuyos representantes, no necesariamente tendrían que provenir de la profesión jurídica. 
Para ser miembro del Consejo, se debe cumplir con los requisitos exigidos para ser Vocal de la Corte Suprema. Su nombramiento es por un periodo de cinco años, eligiéndose simultáneamente a los miembros titulares y a sus suplentes. No cabe la reelección inmediata de los Consejeros (L.O. CNM, Art. 4). Los miembros del Consejo no están sujetos a mandato imperativo ante las instituciones que los eligen; pueden ser removidos de su cargo por causa grave, mediante acuerdo del Congreso, adoptado con el voto de los dos tercios del número legal de sus miembros (Art. 157 de la Constitución).

La Ley Orgánica del CNM, que fue aprobada por el Congreso, el 25 de Noviembre de 1994 y publicada en el diario oficial El Peruano el 7 de diciembre de 1994, resultaba un paso previo indispensable para iniciar la marcha del nuevo órgano, tanto por la necesaria reglamentación y desarrollo de los preceptos constitucionales, como por la regulación de los procedimientos para la elección de los consejeros.

La tendencia reciente confirma que el Consejo de la Magistratura es ya una institución propia del Derecho Constitucional latinoamericano, cuya progresiva introducción alcanza a diez Constituciones: Venezuela (1961), Perú (1993), El Salvador (1983), Brasil (1988), Colombia (1991) Ecuador (1992), Paraguay (1992), Argentina (1994), Bolivia (1994) y México (1994).

También están vigentes dispositivos legales que introdujeron el Consejo la Judicatura, en Panamá, en 1987 (en su Código Judicial, aunque como órgano consultivo de la Corte Suprema) y en Costa Rica, en 1993 (vía su Ley Orgánica del Poder Judicial, aunque como órgano dependiente de la Corte Suprema), suman, entonces, doce los países latinoamericanos que han adoptado esta institución. Todo ello demuestra que su adquisición es reciente y su consolidación es aún una tarea pendiente.

Las diversas fórmulas que adopta el Consejo de la Magistratura en los diversos ordenamientos reseñados indican que es un instrumento jurídico creado y adaptado para responder a necesidades reales y muy precisas de la judicatura de cada país, en particular para garantizar la independencia judicial y la especialización en la labor jurisdiccional. Desde esta perspectiva, su vínculo con la creación de institutos de formación de magistrados y con la instalación de una carrera judicial mucho más definida resulta sumamente interesante.

El nombramiento de los Magistrados del Poder Judicial por el Consejo Nacional de la Magistratura es el más adecuado en el Perú y, en general, en los países de Latinoamérica, porque garantiza la independencia del Juez de los poderes llamados políticos (Ejecutivo y Legislativo) y su imparcialidad; aunque sería conveniente que se garantizara a nivel Constitucional su permanencia, mientras no cometa falta o delito que afecte su conducta funcional, vinculada a su probidad e idoneidad. 


\section{A manera de reflexión final}

Es necesario construir un Poder Judicial llamado a articular un sistema más amplio y diversificado de administración de justicia. Para ello se requiere de ciertas condiciones básicas: capacidad, probidad, idoneidad, honestidad manifiesta, y control por la opinión pública.

En una democracia y en un Estado de Derecho, no cabe duda de que la opinión pública tiene una importancia extraordinaria, tanto para fiscalizar el sistema como para respaldarlo y darle fuerza con sus adhesiones. En este sentido, pensamos que la selección de jueces debe hacerse con la participación de esa opinión pública, a fin de lograr la transparencia, sin la cual, ninguna reforma tendrá un resultado positivo. Estamos plenamente de acuerdo con la Dra. Elcira Vásquez Cortéz, cuando dice:

Este concepto nos lleva a definir en la actualidad cual es el perfil académico que requiere desplegar la Amag, a fin de cumplir con el objetivo no sólo de instruir y especializar a los magistrados que aspiran al ascenso en la carrera judicial, así como a los abogados que deseen ingresar en ella, sino sobre todo contar con un programa sólido y coherente que permita esculpir una sólida formación humana y jurídica de la magistratura en su conjunto (...) El juez democrático supone un magistrado que, por encima de cumplir la ley, es decir, por sobre la dimensión normativa de su función, adquiere una actitud crítica frente a las iniquidades e injusticias sociales, sumándose a aquellas voluntades del Estado democrático que persiguen acabar con las falacias y alejarse del Estado burocrático y corporativo que no asume rol ni partido ante tales circunstancias. ${ }^{11}$

11 VASQUEZ CORTEZ, Elcira. “La nueva misión de la Amag”. En: El Peruano, Lima, 26 de enero del 2004, p. 10. 


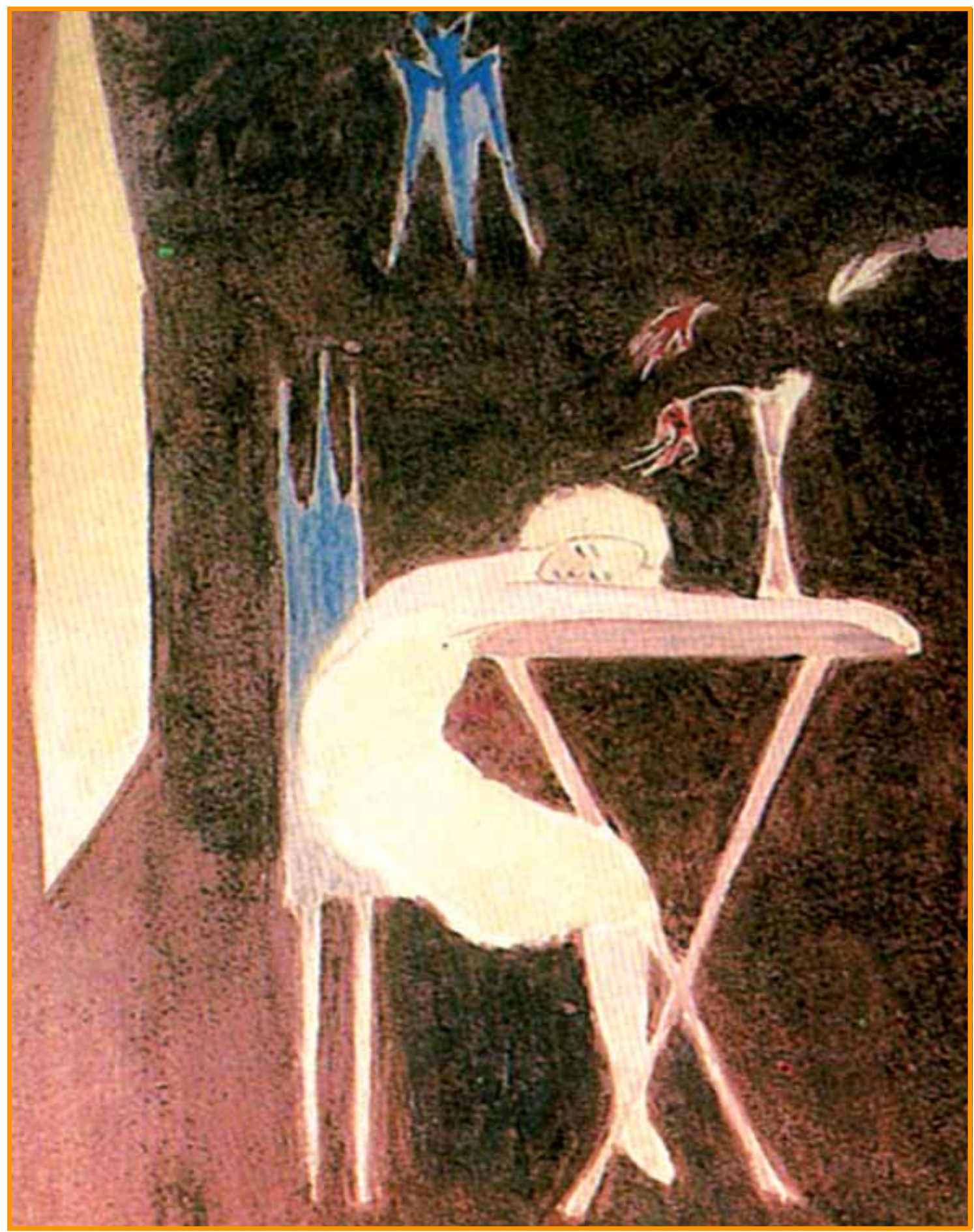

Mujer reclinada sobre brumas 